\title{
Thyroid Nodules : a highly specific molecular and cytological combined predictor of malignancy
}

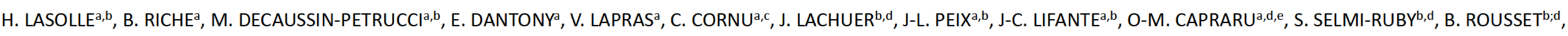
F. BORSON-CHAZOTa,b,d, P. ROYa,b.

aHospices Civils de Lyon, France; bUniversité Lyon 1, France; ' INSERM CIC1407, France; dCentre de Recherche en Cancérologie de Lyon, INSERM U 1052, France; eUniversity of Medicine and Pharmacy, Tirgu Mures, Romania.

Context : Thyroid nodules prediction of malignancy is based on ultrasonographic examination and cytological analysis. Up to $30 \%$ of thyroid nodules remain "indeterminate" after cytological examination using Bethesda Classification.

Objective : This monocentric prospective study aimed to identify a molecular signature to improve the accuracy of preoperative diagnosis of nodules, taking into account the prevalence of the disease and the differential clinical consequences of false-negative and false-positive results.

\begin{tabular}{|c|c|c|}
\hline & Material & \\
\hline $\begin{array}{c}\text { Fine Needle Aspiration } \\
722 \text { patients } \\
\downarrow \\
\text { Surgical Decision } \\
225 \text { patients }\end{array}$ & $\begin{array}{l}93 \text { patients } \\
\text { RIN }<5 \\
\text { or RNA quantity }<40 \mathrm{ng}\end{array}$ & $\begin{array}{l}722 \text { patients, } \\
\text { prospectively included, } \\
\text { underwent Fine- } \\
\text { needle-Aspiration } \\
\text { (FNA) for } 1 \mathrm{~cm} \text { or more } \\
\text { thyroid nodule. One } \\
\text { sample was kept } \\
\text { frozen. } \\
\text { In case of surgical } \\
\text { decision, based on } \\
\text { clinician judgment, } \\
\text { molecular analysis was } \\
\text { performed. }\end{array}$ \\
\hline \multicolumn{3}{|c|}{$\begin{array}{c}\text { The Study Poputation consisted of patients with available } \\
\text { cytological (Bethesda classification), histological and } \\
\text { molecular result. }\end{array}$} \\
\hline
\end{tabular}

Results : cytology and histology

The malignancy prevalence among Bethesda categories was similar to the rates reported in literature (2).

Bethesda level Malignant tumors in the study*

\begin{tabular}{ccc}
\hline & frequencies & percent \\
\hline I & $1 / 10$ & 10.0 \\
II & $0 / 18$ & 0.0 \\
III & $2 / 21$ & 9.5 \\
IV & $9 / 37$ & 24.3 \\
V & $12 / 18$ & 66.7 \\
VI & $22 / 24$ & 91.7 \\
Total & $46 / 128$ & 36.0 \\
\hline
\end{tabular}

* Malignant tumors (46)

papillary thyroid carcinomas (39) anaplastic thyroid cancer (1)

follicular thyroid carcinomas (3) poorly differentiated carcinoma (1)

medullary thyroid carcinomas $(2)$

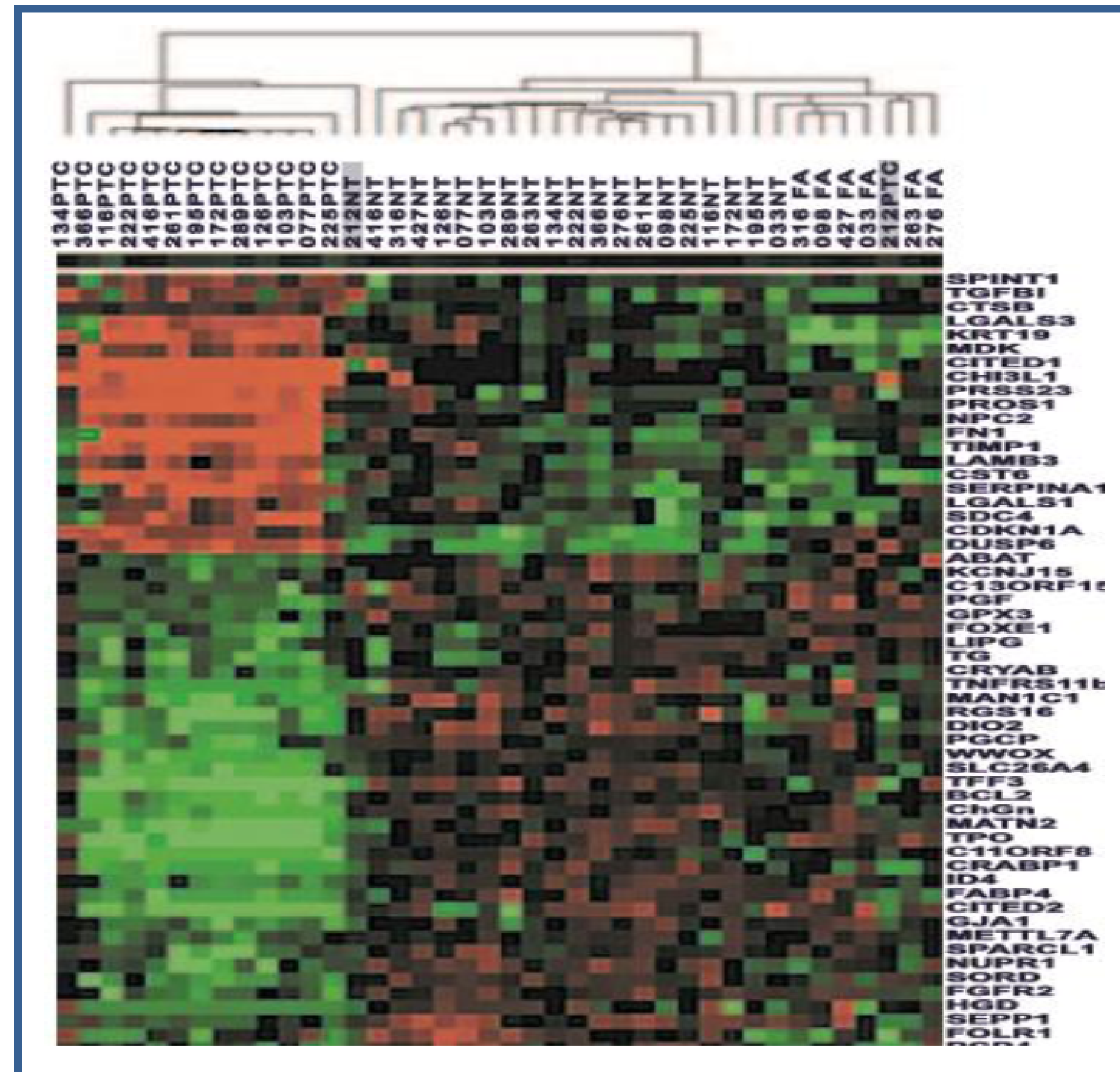

Method : transcriptomic analysis

We performed a transcriptomic analysis of 20 genes selected from a previous study (1) using qPCR on FNA material.

A logistic regression model using genes expression levels as linear covariates generated the molecular predictor.

A gene selection was made using Boostrap method and Akaike information Criterion.

7 genes predicted the best malignancy

\begin{tabular}{ccc}
\hline Gene & $\begin{array}{c}\text { Adjusted OR } \\
{[\mathbf{9 5 \%} \text { Cl] }}\end{array}$ & p-value $^{*}$ \\
\hline FN1 & $2.01[1.12 ; 3.58]$ & 0.015 \\
CITED2 & $0.31[0.17 ; 0.58]$ & $<0.001$ \\
CITED1 & $2.60[1.45 ; 4.65]$ & $<0.001$ \\
CHI3L1 & $0.50[0.29 ; 0.87]$ & 0.012 \\
TFF3 & $0.46[0.26 ; 0.82]$ & 0.005 \\
CDKN1A & $1.71[0.99 ; 2.98]$ & 0.046 \\
CSGALNACT1 & $1.79[0.98 ; 3.28]$ & 0.047 \\
\hline \multicolumn{4}{c}{${ }^{*}$ log-likelihood ratio test }
\end{tabular}

Results : combined predictor performances

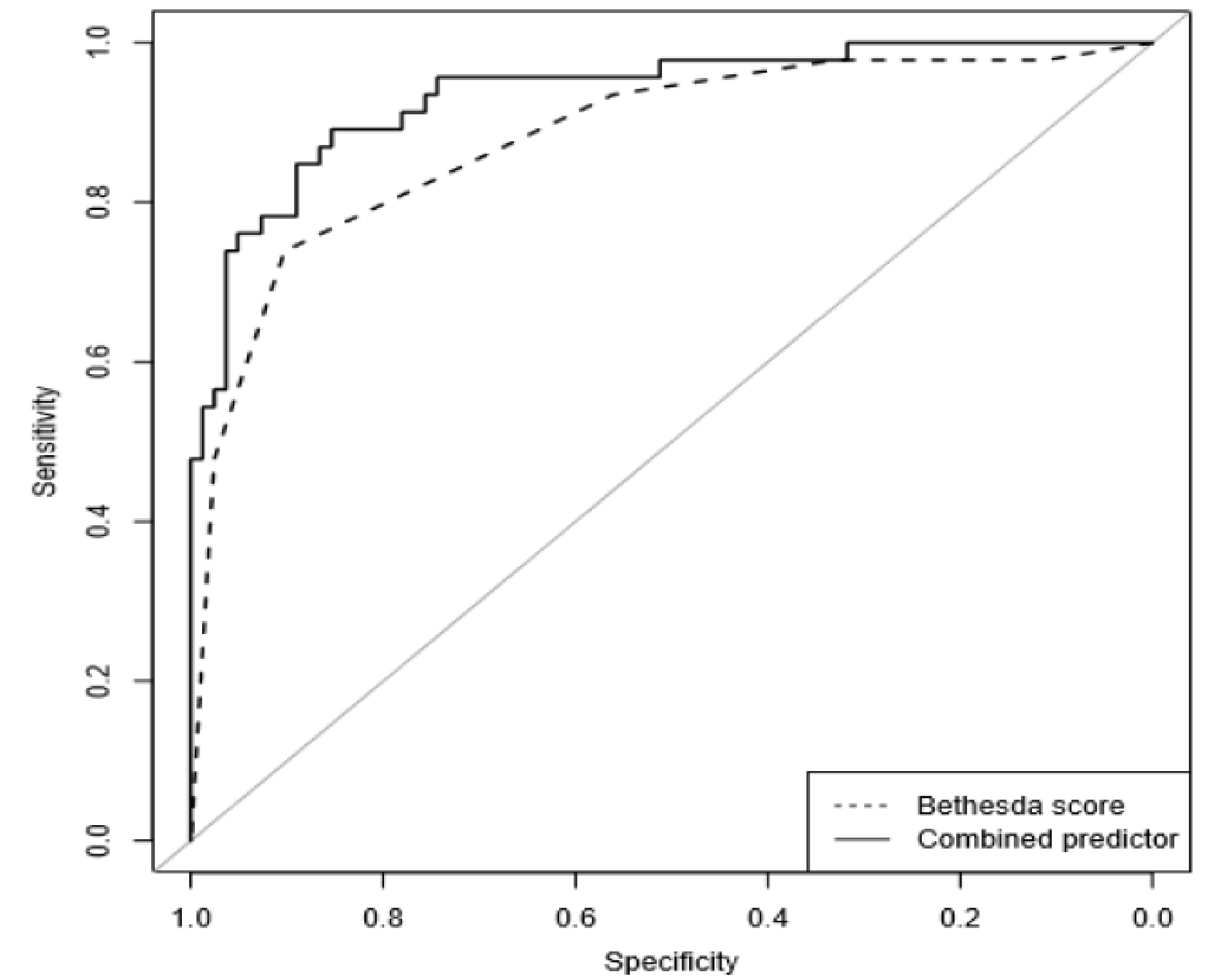

A logistic regression model using two covariates, molecular result (7 genes) and cytological Bethesda category, generated the combined predictor.

The Aera under the curve of the combined predictor was significantly higher than those of Bethesda classification (DeLong test $p=0,004$ ).

In our data-set ( $36 \%$ prevalence of malignancy), the combined predictor achieved a high specificity :

Sensitivity : 76,1 \% [65.22; 97.83]

Specificity : 95,1 \% [85.37; 100.00]

Results : clinical situations and performances

Thyroid cancer prevalence being around $7 \%$ among generic aspirated nodules (2), we optimized the performances considering this prevalence and 2 different benefit-toharm ratios.

Thus, the combined predictor still harboured a high specificity together with an acceptable sensitivity.

\begin{tabular}{|cccc|}
\hline $\begin{array}{c}\text { Probability of } \\
\text { malignant } \\
\text { tumor* }\end{array}$ & Ratio* & Sensitivity & Specificity \\
\hline $\begin{array}{c}\text { In our dataset } \\
36 \%\end{array}$ & $4: 1$ & $95.7 \%[86.96 ; 100.00]$ & $74.4 \%[66.43 ; 93.90]$ \\
$36 \%$ & $1: 1$ & $76.1 \%[65.22 ; 97.83]$ & $95.1 \%[85.37 ; 100.00]$ \\
$36 \%$ & $1: 4$ & $73.9 \%[39.13 ; 86.96]$ & $96.3 \%[95.12 ; 100.00]$ \\
In a virtual population & & \\
$7 \%$ & $4: 1$ & $73.9 \%[52.17 ; 89.13]$ & $96.3 \%[92.04 ; 100.00]$ \\
$7 \%$ & $1: 1$ & $47.8 \%[35.82 ; 82.61]$ & $100 \%[98.78 ; 100.00]$ \\
$7 \%$ & $1: 4$ & $47.8 \%[34.78 ; 71.74]$ & $100 \%[100.00 ; 100.00]$ \\
\hline
\end{tabular}

* The combined predictor model gave a probability of malignancy. The cut-off probability to classify a nodule as malignant or non malignant was set taking into acount the malignancy prevalence.

Then, we introduced the benefit-to-harm ratio concept by weighting the number of false negative and false positive results.

Conclusion: We present the development of a very specific molecular test that may improve the pre-operative diagnosis of thyroid nodules.

Moreover, its performances optimization according to the prevalence of the disease may avoid a reduction in its performances into clinical practice and enables an adaptation to the population of use.

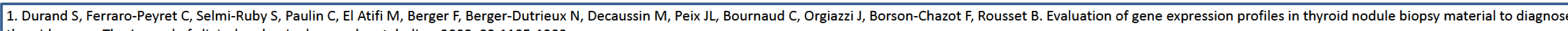
thyroid cancer. The Journal of clinical endocrinology and metabolism 2008; 93:1195-1202

2. Bongiovanni M, Spitale A, Faquin WC, Mazzucchelli L, Baloch ZW. The Bethesda System for Reporting Thyroid Cytopathology: a meta-analysis. Acta cytologica 2012; 56:333-339 